\title{
Erratum to: Ovariectomy impairs spatial memory: prevention and reversal by a soy isoflavone diet
}

\author{
Siomara C. Monteiro - Cristiane B. de Mattos • \\ Juliana Ben • Carlos A. Netto • Angela T. S. Wyse
}

Published online: 28 May 2011

(C) Springer Science+Business Media, LLC 2011

Erratum to: Metab Brain Dis (2008) 23:243-253

DOI 10.1007/s11011-008-9093-6

The 2nd paragraph in the "Animals and reagents" and the 1st paragraph in the "Experimental treatment" of the Material and Methods section (page 245) should be read as though combined in one paragraph. The following note should also be added: "Casein and soy isolated protein diets were prepared according to Franzon et al. (2005) and Reeves et al. (1993). Food intake and body weight were examined weekly. Both diets were isocaloric."

The full reference to the above is as follows: Franzon F, Chiarani F, Mendes RH, Belló-Klein A, Wyse ATS (2005) Dietary soy prevents brain $\mathrm{Na}^{+}, \mathrm{K}^{+}$-ATPase reduction in streptozotocin diabetic rats. Diabetes Res Clin Pract 69:107-112.

Data included in Table 1 has raised debate and should not be considered with the paper.

These corrections do not change the results and conclusions of the work.

The online version of the original article can be found at http://dx.doi. org/10.1007/s11011-008-9093-6.

S. C. Monteiro • C. B. de Mattos · J. Ben · C. A. Netto •

A. T. S. Wyse $(\square)$

Departamento de Bioquímica, Instituto de Ciências Básicas da

Saúde, Universidade Federal do Rio Grande do Sul,

Rua Ramiro Barcellos, 2600-Anexo,

CEP 90035-003 Porto Alegre, Rio Grande do Sul, Brazil

e-mail: wyse@ufrgs.br 